DOI 10.37882/2223-2966.2020.10.10

\title{
КОНЦЕПЦИЯ КОМПЛЕКСА СРЕДСТВ МАТЕМАТИЧЕСКОГО МОДЕЛИРОВАНИЯ И ИСПЫТАТЕЛЬНОЙ УСТАНОВКИ ДЛЯ АВАРИЕСТОЙКИХ ТОПЛИВНЫХ СИСТЕМ ВЕРТОЛЁТОВ
}

\section{THE SET OF MATHEMATICAL MODELLING TOOLS AND TEST FACILITY CONCEPT FOR CRASH-RESISTANT FUEL SYSTEM \\ S. Grachev \\ D. Smagin \\ R. Savel'ev}

Summary: The article considers the set of mathematical modelling tools and test facility concept for crash-resistant fuel system. The main requirements for advanced crash-resistant fuel system are based on aviation aircraft certification rules. A distinctive feature of the concept discussed in this article is a comprehensive development for creating mathematical modeling tools and test facility. The solution includes the complete digital model of the tested system and full-scale test facility that includes rotating platforms for simulation different spatial helicopter positions and equipment complex.

The article presents description of full-scale test facility key elements and mathematical model units.

This solution makes it possible to ensure combined full-scale and digital testing of crash-resistant fuel system at the all stages of helicopter lifecycle.

Keywords: mathematical model, crash-resistant fuel system, test facility, one-dimensional model, three-dimensional model, helicopter.
Грачев Сергей Васильевич

ФГБОУ ВО «Московский авиационный институт (национальный исследовательский университет)»

s-gra2004@mail.ru

Смагин Денис Игоревич

ФГБОУ ВО «Московский авиационный институт (национальный исследовательский университет)» 79637587781@yandex.ru

Савельев Роман Сергеевич

ФГБОУ ВО «Московский авиационный институт (национальный исследовательский университет)»

r_sr@inbox.ru

Аннотация: В данной статье рассмотрена концепция комплекса средств математического моделирования и испытательной установки для АСТС (авариестойких топливных систем) вертолётов. Основные требования, предъявляемые к перспективным авариестойким топливным системам, базируются на авиационных правилах. Отличительной особенностью концепции, рассматриваемой в данной статье, является комплексная разработка по созданию средств математического моделирования и испытательной установки. Решение включает в себя как полную цифровую модель испытуемой системы, так и натурную испытательную установку, включающую в себя поворотные платформы для имитации различных пространственных положений вертолёта, а так же комплекс технологического оборудования.

В статье представлены описания ключевых элементов натурной испытательной установки и модулей математической модели.

Данное решение позволяет обеспечить совместное проведение натурных и «цифровых» испытаний топливной системы на всех стадиях жизненного цикла вертолёта.

Ключевые слова: математическая модель, авариестойкая топливная система, испытательная установка, одномерная модель, трехмерная модель, вертолет.

Для обеспечения совместного проведения натурных и «цифровых» испытаний топливной системы на всех стадиях жизненного цикла вертолёта целесообразно интегрировать между собой использование современных методов моделирования и натурных отработок [6, 7].

Выполнением проекта по созданию комплекса средств математического моделирования в совокупности с испытательной установкой для сопровождения процессов проектирования, испытаний и дальнейшей эксплуатации авариестойкой топливной системы современного вертолета занимается МАИ и АО «ОКБ «Кристалл» в рамках реализации постановления Правительства РФ от 09.04.2010 N 218 (ред. от 21.07.2016). 


\section{Комплексный подход К испытаниям топливных систем}

Объектом испытаний является авариестойкая топливная система вертолёта, включающая в себя размещённые в топливных контейнерах (элементах каркаса) вертолёта топливные баки и внутри- и внебаковые монтажи [8-10].

В рамках создания комплекса средств математического моделирования в совокупности с испытательной установкой МАИ проанализированы основные требования к перспективным авариестойким топливным системам вертолётов и определён следующий перечень пунктов Авиационных правил АП-29 [11-13]:

1. АСТС (авариестойкая топливная система) должна быть приспособлена для заправки под давлением, с давлением на входе в заправочную горловину до 5,0 бар включительно.

2. При централизованной заправке топливом АСТС должна обеспечивать возможность частичной заправки топливом.

3. Топливная система обеспечивает подачу топлива к каждому двигателю с расходом не менее 100\% расхода топлива, требуемого для всех эксплуатационных условий и маневров, подлежащих одобрению для винтокрылого аппарата. Соответствие демонстрируется испытаниями и моделированием в ходе которых обеспечивается выполнение нижеперечисленных требований, за исключением таких комбинаций условий, существование которых будет признано невероятным.

4. Исключена возможность перетекания такого количества топлива, которое бы привело к вытеканию топлива через дренажную систему бака при любых возможных условиях полета.

5. Для каждого топливного бака установлен невырабатываемый остаток топлива, при котором наблюдается первый признак нарушения работы двигателя при наиболее неблагоприятных условиях подачи топлива на всех предполагаемых эксплуатационных режимах и маневрах винтокрылого аппарата. В описанных режимах производится забор топлива из данного бака.

6. Каждый топливный бак выдерживает без повреждений вибрации и инерционные нагрузки. А также нагрузки от веса топлива и элементов конструкции, которые могут воздействовать на бак при эксплуатации.

7. Каждый топливный бак имеет расширительное пространство объемом не менее $2 \%$ от общей емкости баков. При нормальном стояночном положении винтокрылого аппарата на земле исключена возможность непреднамеренного заполнения этого пространства.

8. АСТС должна обеспечивать выработку топлива заднего бака на всех высотах полета при всех эксплуатационных пространственных положениях вертолета.

9. АСТС должна сохранять работоспособность и обеспечивать хранение и подачу топлива в двигатели в количестве, достаточном для всех эксплуатационных положений вертолета, в том числе, на маневренных режимах его полета при изменениях пространственного положения.

10. Время заправки внутренних баков АСТС независимо от способа заправки не должно превышать 10 мин.

По результатам анализа требований к перспективным авариестойким топливным системам вертолётов, а также существующих решений по проведению натурных испытаний принято решение выделить две основные группы испытаний:

- непосредственное функционирование системы при имитации различных пространственных положений вертолёта;

- испытания на плескание с одновременным воздействием заданных вибрационных нагрузок.

В соответствии с выделенными группами в состав испытательной установки (рисунок 1) входят следующие компоненты:

Поворотная платформа (ПП-1), предназначенная для проверки работоспособности АСТС при изменениях пространственного положения её компонентов по крену и тангажу. Изменение положения компонентов АСТС по этим двум углам поворота летательного аппарата может быть выполнено как раздельно для каждого направления, так и совместно для обоих направлений. Изменение пространственного положения испытуемой АСТС может быть выполнено как в дискретном, так и в непрерывном режиме.

Поворотная платформа (ПП-2), предназначенная для испытаний на колебание (качание) и вибрацию топливной системы вертолета. Главным отличием от первой платформы является обеспечение перемещения относительно одной оси с заданной (в соответствии с требованиями АП-29 - от 16 до 20 циклов в минуту) скоростью при непрерывном воздействии вибрационной нагрузки заданной амплитуды и частоты.

\section{Математическая модель}

Для снижения рисков при проектировании АСТС, а также для сокращения объема и стоимости сертификационных и летных испытаний, создается уникальный комплекс математического моделирования и испытательной установки для отработки системы на всех возможных режимах эксплуатации. Комплекс включает в 


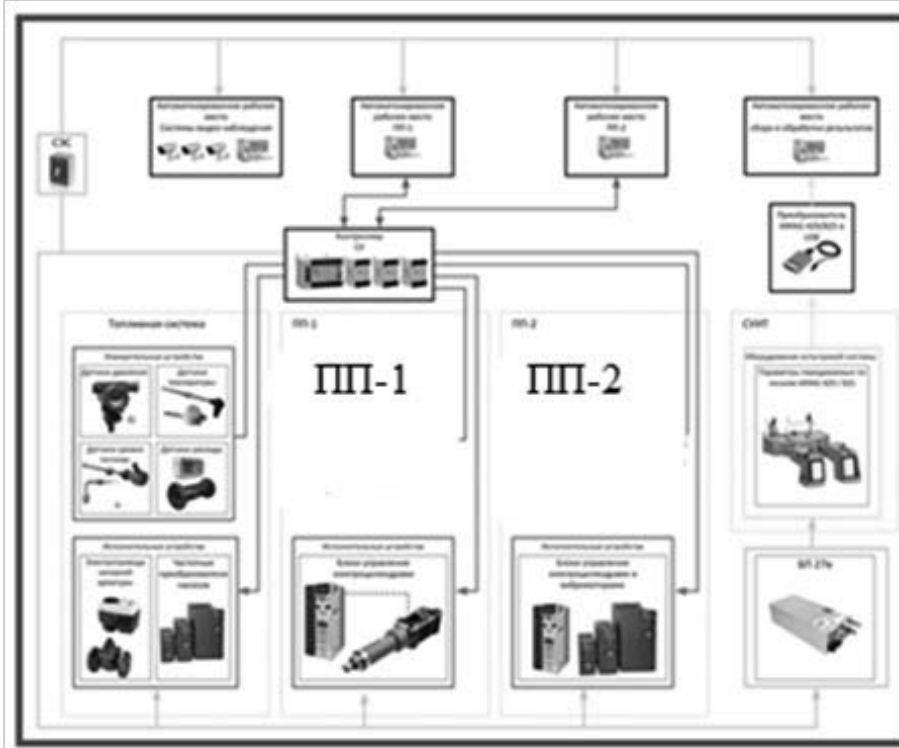

Kommenc cpeacts matematreckoro MOAONDOBOSH

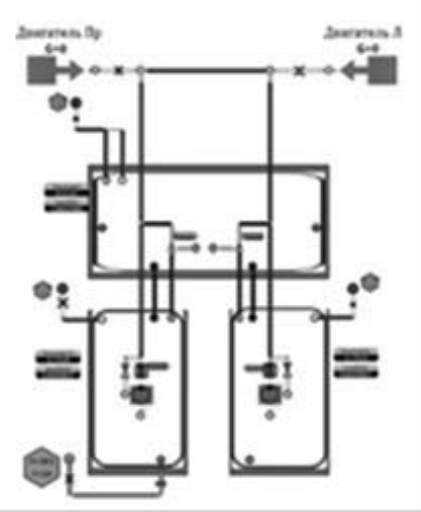

Рис. 1. Блок схема испытательной установки

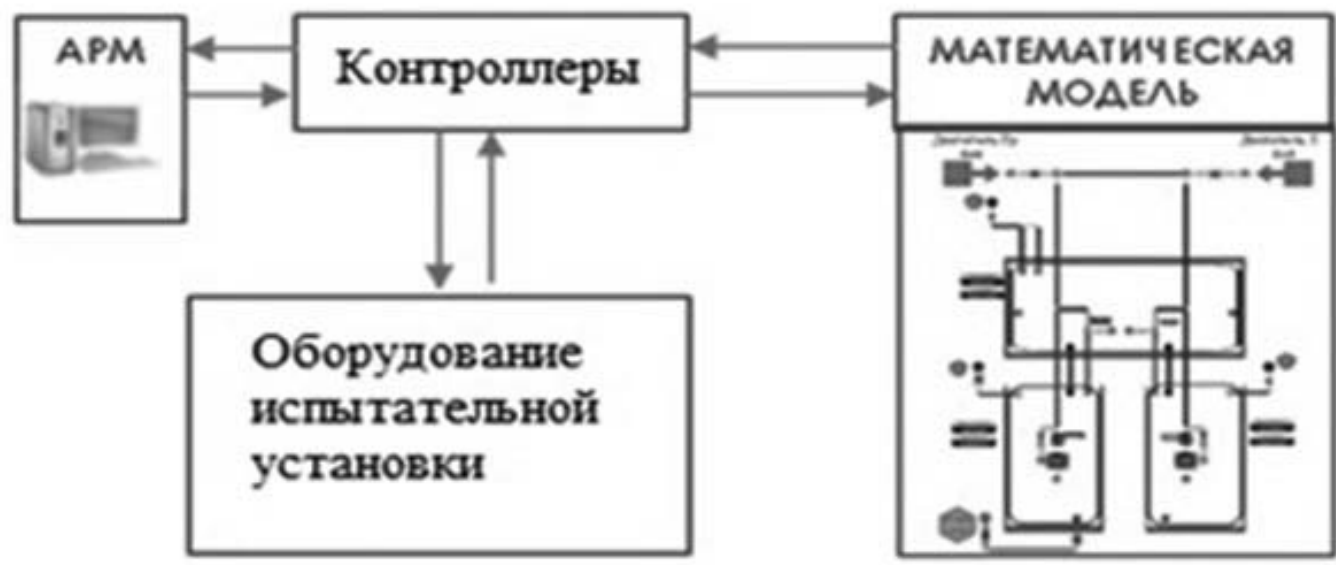

Рис. 2. Взаимосвязь математической модели и испытательной установки

себя как полную цифровую модель всей системы, так и установку содержащую две натурные платформы для имитации различных режимов работы АСТС [14].

Стоит отметить, что в настоящий момент только совместное применение математических моделей и натурной экспериментальной установки, которые образуют единый испытательный комплекс, позволит рационально и с минимальными затратами провести необходимый перечень работ для подтверждения технических требований, предъявляемых к АСТС [15].

Комплекс математического моделирования имеет и состоит из следующих модулей:
Одномерная математическая модель, предназначенная для моделирования функционирования системы, управления и контроля;

Трёхмерная математическая модель, предназначенная для моделирования отдельных узлов и агрегатов с целью получения пространственного распределения характеристик;

Опциональная трёхмерная модель прочности для наиболее критических с точки зрения обеспечения авариестойкости узлов и агрегатов. Она предназначена для моделирования поведения элементов системы - «слабых звеньев» в условиях воздействия заданных нагрузок. 
Для оптимизации процесса моделирования целесообразно проведение совместного расчёта в одномерной и трёхмерной постановке задачи для моделирования процессов заправки топлива и размещения сигнализаторов уровня топлива при различных пространственных положениях топливных баков. Данные расчёты позволяют подтвердить соответствие разрабатываемой системы требованиям сертификационного базиса в части проверки полной заправочной вместимости, времени заправки, корректной работы сигнализаторов, наличие пространства для температурного расширения топлива.

Связь оборудования испытательной установки и комплекса математического моделирования осуществляется через контроллеры системы управления испытательной установкой с выводом результатов работы на отдельный компьютер (C).

Трёхмерная математическая модель базируется на расчетных методах, использующих CFD коды. Полнота описания процессов такими кодами дает возможность с помощью методов вычислительной гидродинамики учитывать геометрические особенности конструкции и различные положения в пространстве, которые не могут быть корректно описаны при построении одномерных математических моделей.

Комплекс средств математического моделирования позволяет моделировать все основные режимы работы топливной системы в соответствии с требованиями АП29.

\section{Системы и технологическое оборудование авариестойкой системы}

Технологическое оборудование и системы, предназначенные для обеспечения снабжения подачи и слива керосина в топливные баки объекта испытаний, электропитания, управления и контроля:

Система заправки и слива топлива. Система подачи топлива обеспечивает следующие функции:

Подачу топлива в объект испытаний из технологической ёмкости с регулируемым расходом и давлением для имитации различных режимов заправки;

- Фильтрацию и сепарацию топлива;

- Запорную арматуру с автоматическим и ручным закрытием;

- очки подключения к порту централизованной заправки или горловине открытой заправке.

Система слива топлива обеспечивает следующие функции:

- Слив топлива из объекта испытаний в технологическую ёмкость штатными насосами объекта ис- пытаний;

- Слив топлива из объекта испытаний в технологическую ёмкость при неработающих штатных насосах объекта испытаний;

- Управление аварийным сливом топлива из технологической ёмкости в топливохранилище по пневматическому сигналу в случае возникновения пожара.

\section{Система электроснабжения:}

Система электроснабжения (СЭС) установки разделена на силовую сеть $3 \phi$ х 380В 50Гц, от которой запитаны шкафы управления платформ ПП-1 и ПП-2, систем подачи и слива топлива, а также, на стабилизированную, оборудованную источниками бесперебойного питания, однофазную сеть 220B 50Гц, питающую автоматизированные рабочие места (АРM), оборудование локальной сети, серверы и систему сбора, регистрации, визуализации, обработки и документирования результатов испытаний.

\section{Система управления:}

Конструктивно система управления (СУ) состоит из отдельных шкафов управления для поворотных платформ (ПП-1 и ПП-2), систем подачи и слива топлива, систем наддува, вакуумирования и вентиляции.

Аппаратное решение СУ ПП-1 и ПП-2 создано на базе частотных преобразователей, поставляемых вместе с электроприводами механизмов поворота и вибрационного оборудования, а также контрольно-измерительной аппаратуры и программируемых логических контроллеров (ПЛК).

\section{Зак^ючение}

В данной статье были проанализированы основные решения для испытаний топливных систем летательных аппаратов, применяемые в настоящее время как в России, так и за рубежом.

Альтернативой существующим решениям является комплексный проект по созданию средств математического моделирования и испытательной установки, разрабатываемый Московским Авиационным Институтом.

Испытательная установка, в состав которой входят поворотные платформы, технологические оборудование и средства математического моделирования, позволяет проводить как исследовательские, так и квалификационные испытания АСТС.

Результат комплексного проекта предназначен для сопровождения процессов проектирования, испытаний и дальнейшей эксплуатации авариестойкой топливной системы современного вертолета. 


\section{ЛИТЕРАТУРА}

1. Smagin D.I., Savelev R.S., Satin A.A. Methods for the Design of Modern On-Board Systems of Advanced Aircraft // 2019 IEEE 10th International Conference on Mechanical and Aerospace Engineering (ICMAE). Brussels, Belgium, 2019. Pp. 97-101.

2. Маковецкий М.Б., Пугачев Ю.Н., Смагин Д.И., Ткаченко И.О. Обеспечение нового качества авиатехники. Проектирование, изготовление и испытания мягких топливных баков авариестойкой топливной системы вертолетов // Качество и жизнь. 2018. № 4 (20). С. 382-387.

3. Системы оборудования летательных аппаратов: Учебник для С40 студентов высших технических учебных заведений / М.Г. Акопов, В.И. Бекасов, В.Г. Долгушев и др.; Под ред. А.М. Матвеенко и В.И. Бекасова. 3-е изд., исправл. и доп. М.: Машиностроение, 2005. 558 с.

4. Sundararajan V. What is Modelling and Simulation and Software Engineering // Centre of Development and Advanced Computing. 2012. Vol. 1. No. 1.

5. Погосян М.А., Савельевских Е.П., Шагалиев Р.М., Козелков А.С., Стрелец Д.Ю., Рябов А.А., Корнев А.В., Дерюгин Ю.Н., Спиридонов В.Ф., Циберев К.В. Применение отечественных суперкомпьютерных технологий для создания перспективных образцов авиационной техники // Вопросы атомной науки и техники. Серия: математическое моделирование физических процессов. 2013. № 2. С. 3-18.

6. Raymer D.P. Aircraft Design: A conceptual approach. Virginia: America Institute of Aeronautics and Astronomics, 2006.

7. Черников М.С., Лотоцкий А.М. Разработка имитационной модели конструкторско-технологической подготовки заготовительно-штамповочного производства в условиях комплексного применения цифровых технологий // Конференция «Системы управления авиастроительным предприятием». 16-17 октября 2014 г. № 16 (1-5). С. 1635-1639.

8. Пермяков С.Н., Савельев Е.А. Исследование проблем создания авариестойкой топливной системы вертолета // Известия Самарского научного центра Российской академии наук. 2014. Т. 16. № 1(5). С. 1536-1539.

9. Leshchiner L.B., Ul'yanov I.E. Aircraft fuel systems design. Moscow, 1975. 318 p.

10. Hayden M.S., Shanahan D.F., Chen L-H., Baker S.P. Crash-resistant fuel system effectiveness in civil helicopter crashes // Aviation, Space, and Environmental Medicine. 2005. № 76 (8). Pp. 782-785.

11. Flight Controls. Available at: www.faa.gov. Date of publication: January, 01, 2014.

12. Federal Aviation Regulations. Part 29 - Airworthiness Standards: Transport Category Rotorcraft.

13. Смагин Д.И., Сатин А.А., Савельев Р.С., Старостин К.И., Суздальцева Д.С., Серебрянский С.А. Концепция создания комплексной математической модели летательного аппарата, включающей основные бортовые системы // Качество и жизнь. 2018. № 4 (20). С. 397-403.

14. Smagin D.I., Starostin K.I., Saveliev R.S., Kobrinets T.A., Satin A.A. Application of this software Simintech for mathematical modeling of various onboard systems of aircraft // Computational nanotechnology. 2018. № 3. Pp. 9-15.
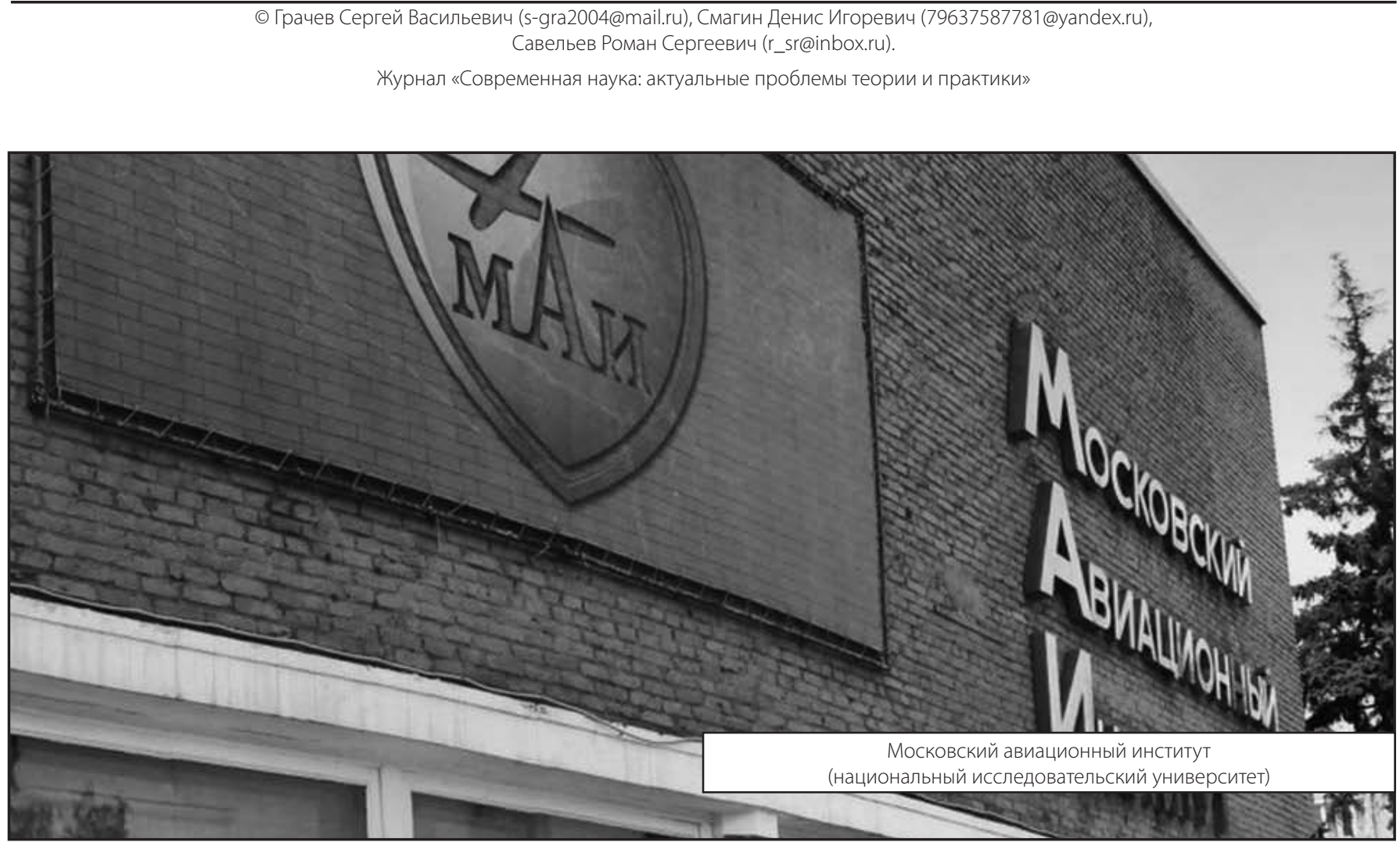